\title{
Misinterpretation of histopathological results as an important risk factor for unneeded surgery - case report of a "near miss" event in a pregnant woman Sigbjørn Løes*1,2 and Knut Tornes ${ }^{1,2}$
}

\author{
Address: ${ }^{1}$ Department of Oral and Maxillofacial Surgery, Haukeland University Hospital, Jonas Lies vei 65, N-5021 Bergen, Norway and ${ }^{2}$ Dept. of \\ Oral Surgery and Oral Medicine, Faculty of Medicine and Dentistry, University of Bergen, Årstadvn. 17, N-5009 Bergen, Norway \\ Email: Sigbjørn Løes* - sigbjorn.loes@odont.uib.no; Knut Tornes - knto@helse-bergen.no \\ * Corresponding author
}

Published: 5 June 2008

Patient Safety in Surgery 2008, 2:14 doi:10.1 186/1754-9493-2-14

This article is available from: http://www.pssjournal.com/content/2/I/I4

(c) 2008 Løes and Tornes; licensee BioMed Central Ltd.

This is an Open Access article distributed under the terms of the Creative Commons Attribution License (http://creativecommons.org/licenses/by/2.0), which permits unrestricted use, distribution, and reproduction in any medium, provided the original work is properly cited.

\begin{abstract}
The oral cavity may exhibit a vast number of pathologic conditions, often dealt with by different medical disciplines. Combined with a substantial variation in clinical appearance, an accurate diagnosis may provide difficult to establish in selected cases. Histopathological investigations are therefore mandatory for correct diagnosis and adequate treatment. We describe a common, truly benign condition in the oral cavity, which due to histopathological misinterpretation was planned for major surgery and subsequent chemotherapy. This was avoided by spontaneous regression of the lesion. The case illustrates that uncritical trust in laboratory diagnostic tests may lead to severe mistreatment.
\end{abstract}

\section{Background}

The oral cavity may exhibit a myriad of expansive lesions, including cysts, reactive lesions, and benign and malignant neoplasms. Additional laboratory examinations are therefore often used to specify the diagnosis. However, the clinical impact of errors committed in the laboratory is poorly described $[1,2]$. Recent data suggest that errors in cancer diagnosis may occur in more than $10 \%$ of reviewed specimens [1]. We report a case illustrating that modern diagnostic tools in some cases may confuse and mislead, rather than clarify a certain condition.

\section{Case report}

A woman aged 31 years experienced in her fifth, and only successful, in vitro fertilization attempt, after approx. 20 weeks of pregnancy a growing tumour palatinally to tooth 22 (Figure 1). She also noticed that her upper front teeth loosened, and considerable spontaneous bleeding occurred from the tumour. Dental X-rays showed an associated osteolytic process. She was referred to the hospital maxillofacial surgery dept. where the lesion, although somewhat atypical, was clinically recognised as a pyogenic granuloma, a condition not uncommon in the gingiva during pregnancy. The loose teeth could be explained by a possible necrotic tooth with an apical infection, and this tooth was therefore subject to root canal treatment without any effect. The lesion was excised, and remarkably, the histopathologic investigation diagnosed, with considerable uncertainty, an angiosarcoma, or possibly a Kaposis's sarcoma. Staining for Reticulin and immunohistochemical investigation, although of variable quality, showed positive Factor VIII (Figure 2) and Mac 387 (antihuman-myeloid/histiocyte antigen), indicating endothelium and blood vessel proliferation [3]. Hemosiderin staining and immunohistochemical analyses for Lymphocyte common antigen, Keratin and S-100, the latter 


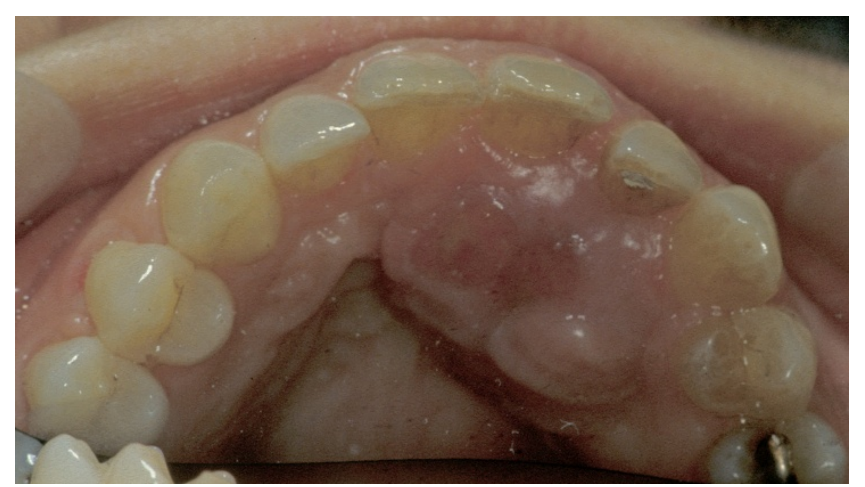

Figure I

The clinical presentation of the tumour (in mirror).

showing crista neuralis-derived cells, were negative. Due to the possibility of a Kaposi's sarcoma, the patient was HIV tested with a negative result. CT scan showed destruction of the alveolar crest in the actual area, and a soft-tissue tumour approx. $2 \mathrm{~cm}$ in diameter (Figure 3). Skeletal scintigraphy showed increased Tc uptake in the actual area. A comprehensive treatment plan was lined up, including resection of the maxilla. As part of the preparations for tumour treatment, the patient delivered short time later two healthy twin boys by caesarean section.

A few days after delivery, just before surgery was to be executed, the palatinal tumour spontaneously regrediated, and disappeared totally within weeks. Her teeth also fastened. The histopathologic diagnosis, unrelated to the clinical development, had at this point been revised to a possible hemangiopericytoma or a hemangiopericytomalike lesion.

Two years later, the patient again became pregnant (extrauterine), and after about a month, a new tumour, similar to the previous and at the very same position, occurred. This also disappeared spontaneously after abortion.

\section{Discussion}

Pyogenic granuloma is considered a reactive lesion, quite common in the oral cavity. It may clinically mimic several other lesions, including malignancies. The so-called pregnancy tumour is a pyogenic granuloma that seems to appear more easily in the gingiva during pregnancy due to hormonal influence. It can be fast-growing and reach a considerable size. After delivery or termination of pregnancy, they most often disappear spontaneously. The histopathology shows proliferating endothelial cells, the stroma is fibrillar, often arranged in lobular aggregates [4]. The actual sections showed collagenous connective tissue with several blood vessels and a cell-rich area with diffuse cell borders and several mitotic cells. Despite the wellknown clinical development of the lesion among the

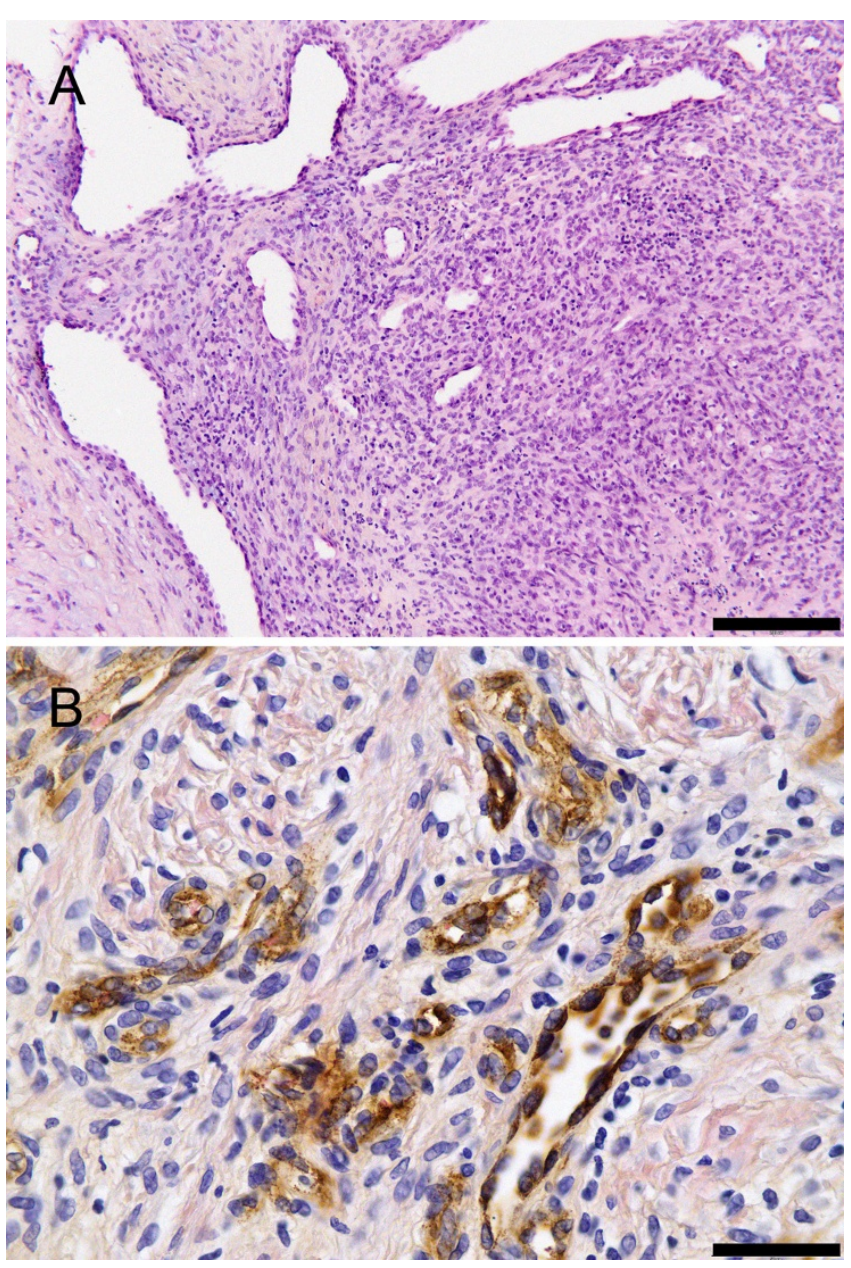

Figure 2

A: Histopathological appearance of the tumour Hematoxylin-Eosin I0x magnification. Scalebar: 200 $\mu \mathrm{m}$. B: Immunohistochemical staining for Factor VIII indicating blood vessel proliferation. Hematoxylin-Eosin. DABstained avidin-biotin peroxidase reaction. $40 \times$ magnification. Scalebar: $50 \mu \mathrm{m}$.

involved pathologists, later re-examinations have not been conclusive concerning histologic diagnosis, and the histopathological appearance seems not typical for any of the previously described entities. Nor is the CT scan typical for a pyogenic granuloma. Recent advances have identified antigens that may help distinguish vasoproliferative tumours $[3,5,6]$, and it is likely that in the future, molecular techniques may play an even more important role in tumour diagnostics and also subsequent choice of treatment [7]. Medical professionals, pathologists included, will probably still commit mistakes, particularly when deprived of or misleaded by e.g. insufficient clinical data [8]. To detect and avoid such errors, different audit regimes have been proposed [9]. In this particular case, most of the recommended audit strategies [9] were per- 


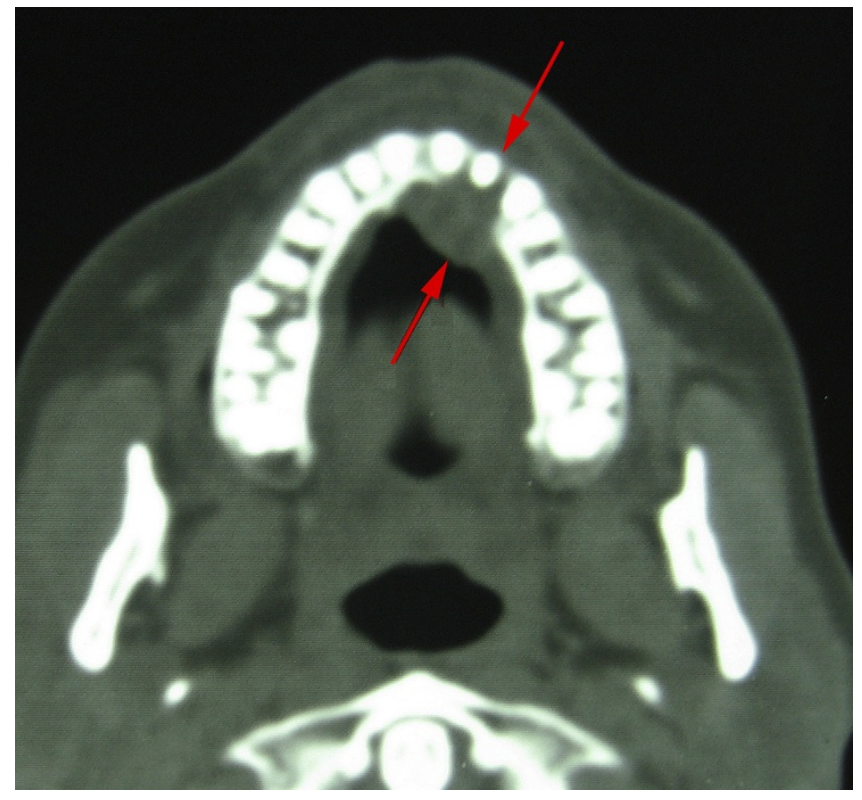

Figure 3

Axial CT scan of the maxilla showing the tumour and destruction of the alveolar process palatinal to tooth 22 (Arrow).

formed. Sarcomas and other relatively rare malignancies are at the Dept. of pathology dealt with by a dedicated group of pathologists, and foreign experts are consulted in special cases, including this one. There are also regular organised discussion meetings between pathologists and surgeons for all malignant tumours to avoid mistakes based on misinterpretation of clinical versus histological data.

The clinical course in this case is highly consistent with a pregnancy tumour. It is, to our best knowledge, not been reported that neither angiosarcomas nor hemangiopericytomas may undergo spontaneous regression. However, the possibility for hormonal and endothelial growth factor influence in vascular tumours during pregnancy is discussed $[10,11]$.

The patient has to this day not experienced any later recurrences of the lesion. Her two twin boys delivered as preparation for tumour treatment have also grown up perfectly healthy.

\section{Conclusion}

As medicine in general becomes increasingly dependent of laboratory investigations, sample analyses, and advanced imaging techniques, it is of great importance to emphasise the value of the clinical consultation as well. The case also reminds us that simple conditions may be misinterpreted, possibly causing serious mistreatment.

\section{Consent}

Written informed consent was obtained from the patient for publication of this case report. A copy of the written consent is available for review by the Editor-in-Chief of this journal.

\section{Declaration of competing interests}

The authors declare that they have no competing interests.

\section{Authors' contributions}

KT was responsible for diagnosis and treatment of the patient and has contributed to the manuscript preparation. SL has re-examined the case, contributed to patient follow-up consultations and drafted the manuscript.

\section{References}

I. Raab SS, Grzybicki DM, Janosky JE, Zarbo RJ, Meier FA, Jensen C, Geyer SJ: Clinical impact and frequency of anatomic pathology errors in cancer diagnoses. Cancer 2005, 104:2205-20I3.

2. Foucar E: Do pathologists play dice? Uncertainty and early histopathological diagnosis of common malignancies. Histopathology 1997, 31:495-502.

3. Ohsawa M, Naka N, Tomita Y, Kawamori D, Kanno H, Aozasa K: Use of immunohistochemical procedures in diagnosing angiosarcoma. Evaluation of 98 cases. Cancer 1995, 75:2867-2874.

4. Jafarzadeh $\mathrm{H}$, Sanatkhani M, Mohtasham N: Oral pyogenic granuloma: a review. J Oral Sci 2006, 48:167-175.

5. Cheuk W, Wong KO, Wong CS, Dinkel JE, Ben-Dor D, Chan JK: Immunostaining for human herpesvirus 8 latent nuclear antigen-I helps distinguish Kaposi sarcoma from its mimickers. Am J Clin Pathol 2004, I 2 1:335-342.

6. Patel RM, Goldblum JR, Hsi ED: Immunohistochemical detection of human herpes virus-8 latent nuclear antigen- $I$ is useful in the diagnosis of Kaposi sarcoma. Mod Pathol 2004, 17:456-460.

7. Lønning PE, Sørlie T, Børresen-Dale AL: Genomics in breast cancer-therapeutic implications. Nat Clin Pract Oncol 2005, 2:26-33.

8. Aarset H, Fagerli UM, Opsjøn SL, Skarsvåg S: A nurse with a rash on her neck. Lancet 1998, 352:540.

9. Ramsay $A D$ : Errors in histopathology reporting: Detection and avoidance. Histopathology 1999, 34:48I-490.

10. Yuan K, Lin MT: The roles of vascular endothelial growth factor and angiopoietin-2 in the regression of pregnancy pyogenic granuloma. Oral Dis 2004, 10:179-185.

II. Annunziato M, Alessio A, Stefano M, Massimiliano G, Marco G, Carmelo A, Giulio M: Hemangiopericytoma in pregnancy: a case report. J Neurooncol 2005, 73:277-278.

Publish with Bio Med Central and every scientist can read your work free of charge

"BioMed Central will be the most significant development for disseminating the results of biomedical research in our lifetime. "

Sir Paul Nurse, Cancer Research UK

Your research papers will be:

- available free of charge to the entire biomedical community

- peer reviewed and published immediately upon acceptance

- cited in PubMed and archived on PubMed Central

- yours - you keep the copyright
BioMedcentral 